empathetically-mediated experiences and to risk the emergence of aspects of one's own self that one would rather not be there. For Goran Aklin from Stockholm, there is nothing quite like patients for bringing out maladaptive aspects of the therapist, second only to spouses and trainers! In training, the therapist's illusions about himself are shredded and the need for a personal therapeutic space to help with this process of self-discovery is great. Emphasis was laid by Sally Box on the feeling response of therapists, in her example co-therapists working with a family, being a mirror of hidden tensions in the inner world of the patient; the underlying mechanism is projective identification. In the transference, being the subject of these confusing identifications has a powerful impact. The interactive element in the therapy relationship was underlined in my presentation on understanding and anticipating potentially damaging combinations of therapist and patient from a Sullivanian interpersonal perspective. In Brazil read 'dangerous' for 'damaging' as in the cases of two homicidal cases presented by David Zimmerman. Derek Steinberg described the acrobatics that were necessary to maintain balance in an adolescent unit with an in-patient who was determined to get herself rejected and Joshua Levy from Toronto described a similar man whose tragic story began in the insecurity of his early relationships and ended with him breaking down the secure frame offered by his therapist.

The dominant emphasis in many of the papers was on identifying and working with the therapist's countertransference; sometimes, I thought, to the point where there was a danger of the patient's concerns being lost to view. Allan Surkis from Montreal had this focus, but his interesting presentation on the use of psychodrama to explore the contemporary and historical parameters of the counter- transference was ambivalently received. With some justification, there was a feeling that the technique was too powerful and that the training programme offered insufficient opportunity to work through the issues raised.

In France, the supervisor is le contrôle and has a normative, superior role. Peter Hildebrand drew our attention to Rioch's elegant analysis of the struggle for mastery between supervisor and supervisee that the former must lose if the trainee is to have his potential facilitated; he advocated a democratic model of supervision which included the supervisor presenting his work to the group. The democratic approach, clearly, frees all the members of a supervisory seminar to express their views and is the antithesis of the French style, and yet the missing dimension in the conference was how to take up the necessary responsibility of evaluating competence. This could be a theme for the next Symposium.

Judith Trowell and A. Hyatt Williams described ways in which institutions may be affected by disaster. A creeping paralysis may result with the management carrying projected feelings of anger and resentment; democratic organisations that can help to work through what has happened survive best. The unstated message was plain; attend to the institution in the same way that you would an overwhelmed trainee. The final address by Anton Obholzer stressed the responsibility of the institution for creating a climate for learning. The structure has to respond to the painful feelings encountered by the trainee in the work and recognise how de-skilled and cut off the beginning therapist may feel on entering the training. The defensive idealising state of dependency must be countered if the goal of facilitating the development of thoughtful, autonomous therapists is to be secured.

\title{
Wessex Drugs Forum Symposium on the Role of Prescribing in the Treatment and Rehabilitation of Drug Misusers
}

\author{
Philip M. Fleming, Consultant Psychiatrist and Director, Wessex Regional Drug Dependency Services
}

This one day symposium was held at the University of Bath on 14 September 1987. It was organised by members of the Wessex Drugs Forum, a multi-disciplinary group of people working in drug services, both statutory and non-statutory within the Wessex Region, and was chaired by the author. The purpose of the symposium was to help clarify some of the issues surrounding prescribing and to consider the need for regional guidelines. About 100 people attended from the Wessex and South West Regions, most of whom had some responsibility for providing services for drug users. Participants included psychiatrists, general practitioners, social workers, community nurses and psychologists.
There were four speakers in the morning session. Dr Virginia Berridge, a social historian, discussed the changes in the availability of opiates in the 19th and 20th centuries; the power struggle between medicine and the state over doctors' independence to prescribe opiates, and the competition between the Home Office and the Health Department over who has control in this area. The announcement during the course of the day that Dr Ann Dally had lost her appeal against a ban imposed by the General Medical Council on her prescribing controlled drugs made one uncomfortably aware that these issues are still relevant today. Dr John Marks of the Liverpool drug clinic 
advocated his well-known views on the need to find a middle way between too restrictive prescribing leading to a flourishing black market and associated crime, and too free supply and availability leading to "epidemic intoxication".

Mr Allan Parry, Director of the Mersey Regional Drug Training Services, discussed the experience of the Liverpool needle and syringe exchange scheme. This was one of the first schemes in the UK to provide clean syringes and needles to injecting drug users on an exchange basis for dirty ones. They see on average 100 drug users each week, many of whom, although they may have been injecting drugs for many years, have never previously attended drug services. Finally, Dr John Strang of the Maudsley Drug Clinic gave a wide-ranging review of the issues around prescribing. He underlined the different types of prescribing and suggested those which might reasonably be undertaken by general practitioners and those which tended to be left to more specialist services.

For the afternoon session, participants divided into a number of discussion groups to look at the following specific issues:

(1) prescribing in rural and urban settings

(2) non-opiate prescribing

(3) opiate prescribing

(4) reducing versus maintenance policies

(5) prescribing for drug using parents.

What were the main themes that emerged from these groups? Firstly, that GPs should be more involved in prescribing, particularly in rural areas far from specialist centres. It was recognised that GPs' attitudes vary and that more training needs to be given, particularly at the vocational level but also at the undergraduate stage. Any GP prescribing to a drug user needs the close support of a community drug team or trained drug worker, particularly for help in counselling. The need for specialist help and guidance, both for GPs and for community drug teams, was emphasised. Though this can be provided by a Regional Drug Team or Drug Dependence Clinic, it was often felt that there should be a local psychiatrist with some experience in managing drug users. Those psychiatrists contemplating setting up a prescribing service were concerned as to whether they could meet the demands that might be put upon such a service. Interestingly, there was no great difference of views over the issue of long term 'maintenance' prescribing. It was seen as one option in certain circumstances where others had not worked.

The potential conflict of social workers on community drug teams was discussed. It was pointed out that if, as a member of such a team, a social worker became concerned at the circumstances of a child of addict parents, his responsibility would be to the welfare of the child. This might mean that the 'confidentiality' of the referral to the team would be compromised if a social services department then became involved. Finally, there was general agreement that some form of Regional guidelines would be helpful, particularly for general practitioners. These should indicate the available services in the Region and give some outline of good practice as far as prescribing is concerned.

Comment Conferences such as this are useful in helping to formulate Regional policies on matters such as prescribing for drug misusers. They tend, inter alia, to indicate where there are gaps in service provision and where there are deficiencies in existing services. The constructive manner in which participants discussed the various issues was noticeable. My impression is that having participants from a variety of disciplines, all interested in providing adequate services for drug misusers, helped to keep a broad focus to the discussion. I would commend this type of meeting to colleagues who may be formulating clinical policies for multi-disciplinary services.

\begin{abstract}
Award
The biennial award in memory of Professor Trevor Gibbens is to be made in October 1988. The Committee responsible for granting the award welcome applications from anyone working with offenders or victims. The award, in the region of $£ 500$, is given to the individual or organisation regarded as best able to use it, and applicants are required to state simply the purpose for which the money is needed.

Applications may be made for equipment, travel etc. and should be sent to Dr Graham Robertson, Secretary, Trevor
\end{abstract}

Gibbens Award, Institute of Psychiatry, De Crespigny Park, London SE5 8AF (to be received by the end of August 1988).

\section{Consultant Appointment}

The South Western Regional Health Authority have informed us that Dr P. M. White has been appointed Consultant in Child and Adolescent Psychiatry in North Devon and commenced his duties there on 14 March 1988. We were previously informed that $\operatorname{Dr} A$. K. Darwish would take up this post (Bulletin, January 1988, 12, 18). 